\title{
The Phenomenological Approach as Epistemologically Support to Legitimize the Position of Oneself to the Other of Psychoanalysis
}

\author{
María del Carmen Rojas Hernández, Paulina Monjaraz Fuentes \\ Universidad Autónoma de San Luis Potosí
}

\begin{abstract}
This work aims to show, in the phenomenology of Husserl, the relevance to seek the elements that give epistemological legitimacy and validity to the conceptualization that brings psychoanalytic theory to account for processes whose explanation necessarily imply to clarify that psychoanalysis, in contrast to psychological treatments, is not based on the effects of a relationship between the participants but in the positioning that each of them occupies relative to the other, particularly when having in mind the concept of transference and recognizing in it the position from which the analyst can give conditions of possibility—-through his interventions—-for which the patient may realize, analyze, and rethink his own position on what constitutes his discomfort. Husserl recaptures the Cartesian base from which opens philosophical reflection to a new area of research "in" consciousness where it is allowed to understand the relationship between subject and object from a new perspective that enables establishing an epistemology that substantiates the rigorous analysis of human subjectivity. Husserl's proposal introduces us to an epistemic field in which it can be shown and, that the psychoanalytic method which enables its effects is precisely the position of the analyst, while by his presence and intervention leads to the other in question, without having to abide by an alien desire, be able to position himself before his own desire. This analysis regarding the desire of oneself is indispensable to understand the elements at play in contemporary psychopathology, as in the present context the intensity of the demands generated in the economic apparatus, are experienced by the subject as arising from himself, erasing traces of his desire that is superseded by social imperatives that crushed and fragmented him.
\end{abstract}

Keywords: epistemology, phenomenologhy, psicoanalysis, transferential relationship, "taking of position”

\section{Introduction}

The central question of our exposition attempting to contribute to the major topic "Why do humans become mentally ill? Anthropological, biological, and cultural vulnerabilities of mental illness" addresses a central issue on the root of mental illness, which is implicit in the necessary taking a position of the psychoanalyst in front of the patient. The core point could be raised as follows: Why the cure from psychoanalysis does not lie in "doing something in the patient," that is, why it does not lie in a technique

María del Carmen Rojas Hernández, Pys.D., Faculty of Psychology, Universidad Autónoma de San Luis Potosí, México; main research field: Psychoanalytic Clinic.

Paulina Monjaraz Fuentes, Ph.D., Faculty of Social Sciences and Humanities, Universidad Autónoma de San Luis Potosí, México; main research field: Phenolomenology and Relationship between Phenomenology and Psychology. 
seeking an intervention that from the outside modifies something that "goes wrong," but rather poses a method that implies taking a position of the analyst, from which the transferential relationship-dissymmetrical position that keeps between themselves analyst and patient-may produce effects, so that the patient changes position with respect to itself, regarding its affections and of course, regarding others.

\section{The Analytic Situation as “Taking a Position”}

From a psychoanalytic perspective, the transferential relationship is understood as the effect of a way to put oneself in front of the other. However, it suits to consider that at different times both Freud ${ }^{1}$ and Lacan $^{2}$ imprinted a historicist character to the notion of transference, as if the effect thereof were that episodes in the life and feelings of the patient be repeated. Rojas ${ }^{3}$ mentions that Freudian documents seem that the transfer would have the effect of filling memory gaps, and therefore, read that way it might seem that the healing of neurosis had to do exclusively with the possibility of remembering traumas, revealing the repressed and in this way a healing process occurs. In a way, also in $\operatorname{Lacan}^{4}$ one can find an interpretative and historical quality of transference when introducing the "a priori” notion. But this historical character is contemporarily rethought as a timeless issue, which is an important contribution to psychoanalytic theory, by introducing the notion of timelessness; repetition turns into an incomplete and inconsistent formulation; repetition can no longer be talked about insofar as there is no logical time register in the unconscious. This timelessness of the unconscious results in a basic argument for introducing rethinking that transference and analytical effects in a healing process, rather than a repetition effect is the effect of a specific form of "putting oneself" in front of the other when occupying the position of analyst in the transferential relationship.

It is at this point where it becomes particularly interesting to retake the contributions of the phenomenological approach for the comprehension of the subjectivity structure, as the radical importance of transference in the direction of psychic illness healing is based in that through this access to the basic structure of subjectivity is enabled, established by the relationship I-thou, not at the reflexive level, but at the constitutive level. ${ }^{5}$ So the analyst when taking the position of another that listens, gives the patient, the possibility through language of hearing itself and be heard, so that the patient recovers or builds a position in front of others. This in turn allows us to comprehend mental illness as a "coming out of oneself," but not "from oneself," but from positions that are unaware of said anchor or affecting it.

From this perspective, it should be specified that Husserl when inaugurating a new research sphere opened in turn new epistemological perspectives, as "putting oneself in consciousness" allows access to the subjectivity structure. This "putting oneself in consciousness" prevents the objectification of subjectivity, causing in such objectification loss of subjectivity, or the loss of the subject. So that, "putting oneself in consciousness" is a step forward not only in philosophical research, but also in scientific research, particularly in the conception of research based on psychoanalysis, precisely because such approach allows us to establish epistemologically the importance that transferential relationship has been understood not as an eternal return, but as a particular form of "placing oneself;" relationship sustained on a position in front of knowledge that slides in and becomes in a position in front of the other.

The analytic situation implies a position that is organized from an initial moment in which a subject "demands" another knowledge that involves knowing about itself that it needs and seeks implicitly in that demand. Therefore, there is a not knowing from the start in an analysis, a non-fundamental and constitutive knowledge that leads to a demand looking for that knowledge in someone else who is assumed. This moment is 
crucial insofar as it allows the other that assumes itself as an analyst to take advantage of that position that is being assumed to place itself there. The analyst already in that position, can deploy specific elements and own of the psychoanalytic device so the subject demanding a knowledge actually finds a constitutive lack that gives it conditions of possibility to renounce the ideals (understood as impossible objects) underlying its suffering; therefore, an encounter with the dissymmetry pointed by desire in the background of the relationship with the other, i.e., of the dissymmetry with the other in its object dimension ${ }^{6}$ will occur. The patient finds, after accepting that constitutive lack, the renunciation to ideals that were tormenting him. That is, he can stop suffering by not getting objects or satisfactions to which it would not have access to, whatever he does. He will no longer go through life by suffering for the impossible.

\section{The Phenomenological Approach as an Epistemological Taking of Position ${ }^{7}$}

Having stated the importance of the analyst's taking of position to enable transference in psychoanalysis, we can make some considerations from phenomenology to support epistemologically why such position of the analyst is a condition without which it is not possible to access subjectivity. For such purpose, the first question to be addressed is: What does it mean taking a position? And why this taking of position is actually the method (the path) in order to access subjectivity?

From the phenomenological approach, it is clear that the only way the human being can experience or its only way to live is IN consciousness. Husserl emphasizes with transcendental reduction that the human person when being a conscious being, a oneself, always is present to himself, and is an egological pole, and from there it is referred to what is not himself. This polarity of the self cannot be denied because the self would stop being self if it stopped being the origin and source of all his experiencing. He cannot stop to be present to himself, and therefore being a constant and uninterrupted (continuous) presence cannot refer to the other without first referring to himself. In short, this polarity of the self cannot be suppressed since the self would no longer be the self without such polarity. Hence, from the phenomenological approach, being a subject, i.e., be a conscious being, implies being structured from oneself, from the self, and therefore all living or all of his experiencing may not be realized but IN the consciousness. ${ }^{8}$ In other words, with nothing the "self" can do, I can do "out of the self." If so, it is understandable why the path of psychoanalysis healing is just one "taking of position" of the analyst, as it is not possible to think of another path that accesses subjectivity if it is not in the position of a self in front of another self, that is, from the structure I-thou. So, it makes no sense to intervene "from the outside" for the cure, that is, any intervention from the outside that attempts to "objectify" the subject implies not to really access to subjectivity.

However, considering that "the task of pure phenomenology is to examine, according to the very essence, the pure self, the original life of consciousness, and unity of the experiences", ${ }^{10}$ what first appears before us to experience is the individual person as experience of oneself; that is what is most present to me is myself. ${ }^{11}$ The pure self is the original source of living, the starting point from which experiences under their objectives that are the objects irradiate. It is the structural form of the individual self, and it is something general that belongs to every conscience, but such individuality of the pure self and his experiences can only be shown as it is not a qualitative difference; it is rather a being-itself-and no other. Therefore, the pure self is something general, but as a source of experiences is an absolute individual, it is this consciousness that lives.

Thus, beyond the empirical experience, and considering the experience from its origin, the subject discovers that the subject of all experiences being experienced, even thinking itself, has himself as source. 
While certainly the experience of oneself is performed through physicality, however, we can consider that even in this case we find ourselves as a spiritual self ${ }^{12}$ in reference to the flow of experiences. Therefore, the subject is found as the source of the acts and states, so "if we first consider the person as subject of the life of the self, then the person is not distinguished from the pure self" (104). ${ }^{13}$

The pure self is a particular form of consciousness that has as structure the same being in tension between two poles, which is a vital center that looks in awake mode in a world in which looks directly into the eyes to a being (another "cogito") and to any object detected as such. ${ }^{14}$ This implies that being subject, even after all the experiences that shape the psychophysical self (individual), is to be structured intentionally, that is, it is to be referred to another. Put more directly, the self cannot be constituted without a thou without another that refers to himself as another self.

In this way, phenomenological approach, when getting in consciousness, allows us to analyze the person from its constitutive oneness; and also, the other person from its being source and origin of his experiences, and not merely as being there in the world, but with a self (a being-oneself). In such a way that the other (the thou) is introduced to the experience in a peculiar way, it presents to us mainly as "origin and sources of his actions," i.e., as "another self" or "another fellow being."

Thus, the living of a conscious subject implies that his living is "putting oneself," i.e., taking a position in front of the other that is not his self (his self being—himself). This living "in consciousness" allows knowing the human being in his identity, that is, in what makes him be identical to himself, and in that sole sense. So that, living in consciousness is the only way of living that has a conscious subject and the basic condition of his subjectivity structure. The only authentic way to approach a subject is taking a position of self to thou, of subjectivity to subjectivity. Any other way would assume an "objectification," deriving in knowledge of everything objective of the individual, but leaving aside precisely his subjectivity. Thus, two approaches to the subject open: the first for being the one that is always present to our consciousness, the self, and the second, the presence of other consciences - alien - that are the others. Knowing the person (subject) placed IN, the consciousness allows us to know him in his identity and otherness, noting that the oneness of the human being is not given only by his substantial unity as a physical body, or by a concatenation of features common to his species or type, as happens with any material or animal body. The oneness of the human being is especially given by the structure of his subjectivity, that is, for being a self that has all referred to himself.

Therefore, the subject "discovering" features that make it common to other human beings is not known, but just knowing what makes him be himself, and this can only be known by taking a position as "another self," i.e., as a thou. So that, to know the person in its oneness, in his subjectivity, necessarily is required to "take a position," a subjective position and not trying to objectify the subject to know him. From here derives one of the essential and diametrically distinct differences that can be established between the psychoanalytic method and any other psychological treatment that following the experimental scientific method seeks by methodological principle, the objective characteristics of the patient to typify the symptom within a common range allowing it to determine or define psychic disease. Instead, psychoanalysis aims to analyze the effects—reaching consciousness or not—of the unconscious as long as cause of the discomfort, so it requires taking a position in front of the patient, in order to access the structure of subjectivity. In that sense, one could say that the transferential relationship allows and encourages access to the deepest essence of the subject, namely, his desire. 
From this phenomenological epistemology, the self is always present to himself as is known to be the original source of the experiences, and the self recognizes the other as another self, precisely for also being source and origin of his own experiences. This I-thou relationship constitutive of subjectivity is what allows the analyst to take a position in front of the patient. Therefore, we can conclude that from the phenomenological approach there is no other way to access the subjectivity structure but on the position of a thou, because the very subjectivity structure implies that the subject cannot not live outside his self, and that other self can only be accessed from the position of a thou. Outside this access path, the self, subjectivity, is not actually accessed, but to an "objectification" where the subject is lost.

Retaking these epistemological assumptions, it is now possible to base from such epistemology that why the psychoanalytic method necessarily implies that the analyst takes a position, and as if this were not so, we could not speak of an analysis of the unconscious, and let alone a "repositioning" of the patient from the analyzed. The subject tends to find that which is not there and with that establishes the dissymmetrical relationship between two different ones and that difference lies in having: One has and the other does not. The one that does not have looks for the one that has, even if he does not know exactly what it is that he seeks and the other has. The one that has does not know what he has; what he knows is that he has what the other is looking for. So that, from the phenomenological approach, one can say that the analytic situation recovers a necessary situation for the subjectivity structure given as such, and that all "being outside" of the constitutive relation I-thou may be the deeper cause of psychic disease.

\section{Notes}

1. Freud, S., The Dynamics of the Transference. Collected Papers, Vol. 2. Hicks Press: USA, 1912/2014, 312-23.

2. Lacan, J. Seminar VIII, Transference. Polity Press: USA, 1961/2015.

3. Rojas, H. María del Carmen (2002). Master’s Thesis, “Transfers and Platonic Eros.” Faculty of Psychology. Universidad Autónoma de San Luis Potosí. San Luis Potosí, México.

4. Lacan, J. Seminar VIII, Tranference. Polity Press: USA, 1961/2015.

5. It is important to clarify the difference between the significance that the constitutive concept in psychoanalysis and phenomenology has. Konstitution in Husserl's phenomenology means transcendental, i.e., that is foundational, therefore, the I-thou structure refers to the structure of the pure self. In constitutive psychoanalysis, it is to make reference to the constitution of the self in its three mythical moments: (a) auto-eroticism; (b) narcissism; and (c) choice of object.

6. Lacan, J. The Four Fundamental Concepts of Psycho-Analysis. Jacques Alain Miller (Editor), 1964/2004.

7. To explain the phenomenological approach, we will draw on some Edith Stein's texts, especially her work Einführung in die Philosophie (Introduction to Philosophy), who as a direct disciple of Husserl developed Pure Psychology more, and her texts are illuminating of the position of her teacher.

8. It should be noted that for psychoanalysis, the symptom or the deeper motivations are conceived in the unconscious. On the other hand, when in phenomenology one talks of consciousness, one talks about the constitutive region, namely transcendental, so such structure or pure self would include the unconscious level about which Freud talked.

9. It is important to note that the concept of "self" in Husserl is not the same as in Freud. The notion of self from the phenomenological approach is a structure in which the continuous flow of experiences (Erlebniss) is sustained, while for Freud the self is the product of successive identifications, which in turn are the path of relinquishing the object, therefore it is said that there is kept the history of all object elections in the self.

10. Stein, Edith, Einführung in die Philosophie. Edith Stein Gesamtausgabe Vol. 8, Hinführung, Bearbeitung und Anmerkungen von Claudia Mariéle Wulf, (Freiburg-Basel-Wien: Verlag Herder, 2004), 105. §292. "Das reine Ich, das ursprüngliche Bewußtseinsleben und die Erlebniseinheiten, die sich aus ihm aufbauen, ihrem Wesen nach zu untersuchen, das ist die Aufgabe der reinen Phänomenologie”.

11. This primacy is neither temporal nor spatial, but precisely transcendental, constitutive.

12. Here the spiritual term generally means that the self is not based on somaticity. This is possible because in its foundation of the pure self, it does not depend on sensory experience, but as experience of the self is an incarnate self.

13. Stein, E., Einführung in die Philosophie. 104, §289. 
14. Cfr. Stein, E., Einführung in die Philosophie. 104, §289. Here Edith Stein notes that this looking can be “awake” (direct) or asleep (indistinct) which could be considered as an allusion to the unconscious.

\section{Works Cited}

Freud, S. The Dynamics of the Transference. Collected Papers, Vol. 2. Clinical Papers, Paper on Technique. USA: Hicks Press, $1912 / 2014$.

Lacan, J. Seminar VIII. Transference. USA: Polity Press, 1961/2015.

Lacan, J. The Four Fundamental Concepts of Psycho-Analysis. Jacques Alain Miller (Editor), 1964/2004.

Rojas, H. María del Carmen. Master’s Thesis, “Transfers and Platonic Eros.” Faculty of Psychology. Universidad Autónoma de San Luis Potosí. San Luis Potosí, México. 2002.

Stein, Edith. Einführung in die Philosophie. Edith Stein Gesamtausgabe Vol. 8. Hinführung, Bearbeitung und Anmerkungen von Claudia Mariéle Wulf, Freiburg-Basel-Wien: Verlag Herder, 2004. 235. 